\title{
Productive experience and specialization opportunities for Portugal: an empirical assessment
}

\author{
Miguel Lebre de Freitas ${ }^{1}$ \& Luis Catela Nunes ${ }^{2}$ \& \\ Rui Costa Neves $^{2}$ \& Susana Salvado ${ }^{3}$
}

Received: 12 September 2013 / Accepted: 2 November 2015 /Published online: 17 November 2015 \# ISEG 2015

Abstract Following Hidalgo et al. (Sci Mag 317: 482-487, 2007), we use the structure of international trade to estimate a measure of "revealed relatedness" for each pair of internationally traded products, which intends to capture similarities in terms of the endowments or capabilities they use in production. Our method departs from the original one, in that we run statistical tests of equality in probabilities, instead of computing conditional probabilities. We estimate a matrix of "Revealed Relatedness Indexes" using 2005 data and we then investigate which "upscale" products in which Portugal didn't develop comparative advantage are more related to products in which the country is currently specialized. The analysis suggests that more than $60 \%$ of Portugal's "upscale opportunities" lie in non-traditional sectors, such as "machinery" and "chemicals".

Keywords International trade $\cdot$ Comparative advantage $\cdot$ PRODY $\cdot$ The Portuguese economy

JEL Classification $\mathrm{C} 14 \cdot \mathrm{F} 14$

Miguel Lebre de Freitas afreitas@ua.pt

1 Universidade de Aveiro and NIPE, DEGEI, Universidade de Aveiro, Campus de Santiago, 3810-193 Aveiro, Portugal

2 Nova School of Business and Economics, Universidade Nova de Lisboa, Lisbon, Portugal

3 Banco de Portugal, Lisbon, Portugal 